\title{
OPEN Analysis of diagnostic delay and its influencing factors in patients with chronic obstructive pulmonary disease: a cross-sectional study
}

\author{
Zhongshang Dai ${ }^{1,2}$, Yiming Ma ${ }^{1,2}$, Zijie Zhan ${ }^{1}$, Ping Chen ${ }^{1 \bowtie}$ \& Yan Chen ${ }^{1 \bowtie}$
}

To explore the status of diagnostic delay and to clarify its potentially influencing factors in patients with chronic obstructive pulmonary disease (COPD). A cross-sectional study was conducted in a Chinese tertiary hospital between July 2019 and February 2020. A total of 408 eligible outpatients with COPD were recruited, and relevant data were collected in the form of questionnaires. Diagnostic delay was compared among different characteristics using the Wilcoxon test and Kruskal-Wallis $\mathrm{H}$ test. Multivariable linear regression analysis was performed to determine the factors related to diagnostic delay. The median (interquartile range [IOR]) duration of diagnostic delay was $230(50-720)$ days. The proportions of COPD patients who chose tertiary, secondary, and first-level hospitals for the first visit were $53.7 \%, 29.9 \%$, and $16.4 \%$, respectively. Additionally, the proportions of patients who underwent pulmonary function tests for the first visit in tertiary, secondary, and first-level hospitals were $74.0 \%$, $24.6 \%$, and $1.5 \%(p<0.001)$, respectively. In terms of characteristics related to diagnostic delay, there was a significant difference in residence, resident manner, COPD assessment test (CAT) score, modified Medical British Research Council (mMRC) dyspnea scale, age, forced expiratory volume in one second (FEV1) \% predicted, and years of education (all $p<0.01$ ). Linear regression analysis showed that significant predictors of diagnostic delay included FEV1\% predicted $(p<0.05)$, resident manner $(p<0.001)$, and years of education $(p<0.01)$. Our study indicates that varying degrees of diagnostic delay may exist in patients with COPD. Measures are needed to intervene in the potential factors associated with diagnostic delay.

Chronic obstructive pulmonary disease (COPD) has become a global public health challenge due to its high prevalence and related mortality ${ }^{1}$. According to the 2013 Global Burden of Disease (GBD 2013) report, COPD has become the third leading cause of death worldwide, with approximately 3 million deaths each year ${ }^{2}$. In China, the results of a latest national survey in 2018 have shown that there are close to 100 million COPD patients, and the prevalence rate in people over 40 years old is $13.7 \%{ }^{3}$. Consequently, early diagnosis and intervention of COPD are of great value for preventing the progression of the disease ${ }^{4}$. Several studies have demonstrated that early intervention in patients with COPD may improve lung function ${ }^{5-7}$; the UPLIFT study showed that early intervention could reduce the number of acute exacerbations of COPD ${ }^{5}$. However, many factors such as physician-related factors, patient-related factors, and the heterogeneity of the disease itself may have an impact on the early diagnosis of COPD ${ }^{8}$. COPD patients generally have insufficient knowledge of the disease and a low awareness rate ${ }^{9}$, which may work together with other factors to cause delays in the diagnosis and intervention of COPD. The China Pulmonary Health $(\mathrm{CPH})$ study showed that only $2.6 \%$ of patients diagnosed with COPD by pulmonary function test knew they had $\mathrm{COPD}^{3}$. A study from South Korea indicated that among male smokers, only $23.8 \%$ were aware of COPD, while $30.5 \%$ had undergone lung function tests ${ }^{10}$. Another study from Denmark showed that $28 \%$ of the smokers did not consider COPD to be a fatal disease ${ }^{11}$.

Medical seeking behaviour refers to the whole process from perceiving symptoms to seeking medical care for the purpose of prevention or early detection of a disease and its treatment ${ }^{12}$. Proper medical seeking behaviour is an important measure for managing an illness and its early treatment, and it also plays a key role in disease transmission and disease control. Diagnostic delay refers to the time interval between the onset of symptoms and

${ }^{1}$ Department of Respiratory Medicine, Second Xiangya Hospital, Central South University, Changsha, China. ${ }^{2}$ These authors contributed equally: Zhongshang Dai and Yiming Ma. ${ }^{\boxplus}$ email: pingchen0731@csu.edu.cn; chenyan99727@ csu.edu.cn 


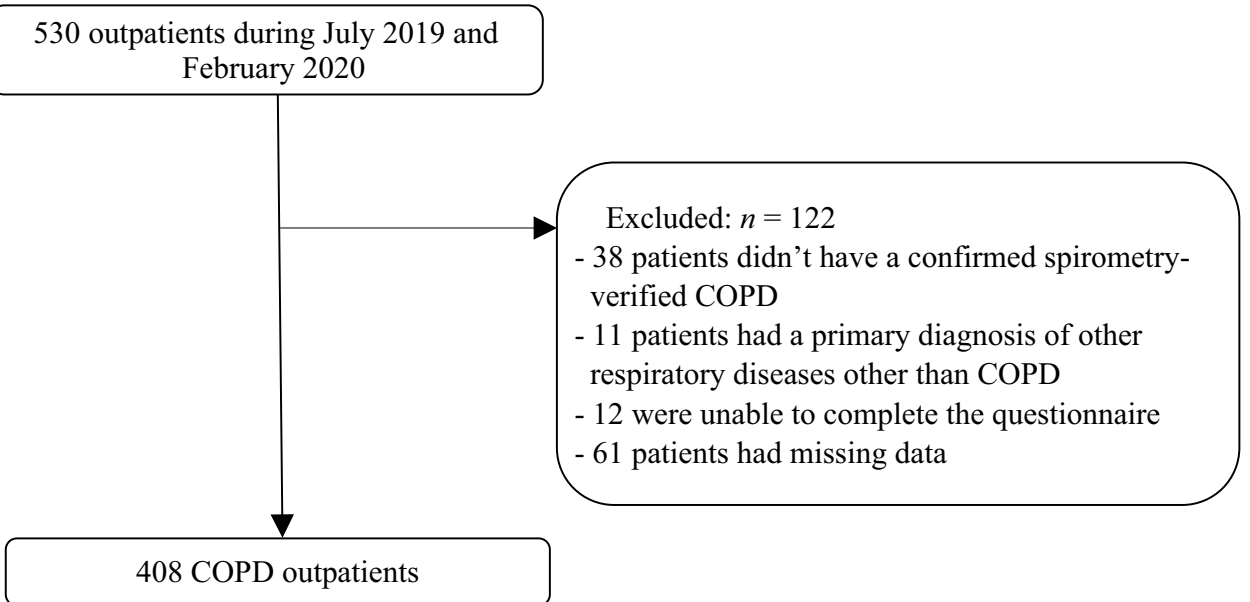

Figure 1. The flowchart of eligible patients. COPD chronic obstructive pulmonary disease.

the date of diagnosis ${ }^{13}$, and it is one of the most important indicators for evaluating medical seeking behaviour. Wang et al. ${ }^{14}$ found that lower awareness and higher age of tuberculosis patients is associated with delayed visits to medical institutions.

However, there have been no studies on the diagnostic delay and the factors influencing it in patients with COPD in China. Considering the large population of COPD patients in China, we aimed to conduct a comprehensive analysis to investigate the status of diagnostic delay of COPD patients and clarify its potentially influencing factors, which may be of great value in the early diagnosis and intervention of COPD.

\section{Methods}

Study design. This is a cross-sectional study of outpatients with COPD in a large Chinese tertiary teaching hospital. Ethical approval was obtained from the ethics committee of the Second Xiangya Hospital, Central South University. Informed consent was obtained from all the study participants. All methods were performed in accordance with the ethical standards formulated in the Helsinki Declaration.

Study participants and procedures. Patients were included if they had been diagnosed with COPD according to the GOLD 2019 criteria $^{15}$, and the age ranged from 35 to 80 years. All patients visited the respiratory outpatient department of the Second Xiangya Hospital from July 2019 to February 2020 and were in a stable condition. The eligible criteria were as follows: (1) who had a confirmed spirometry-verified COPD per the GOLD 2019 report, which was defined as post-bronchodilator forced expiratory volume in one second (FEV1)/ forced vital capacity $(\mathrm{FVC})<0.70$; (2) who had no primary diagnosis of other respiratory diseases other than COPD (including asthma, bronchiectasis, pulmonary tuberculosis, pneumonia, pulmonary interstitial fibrosis, lung cancer, pulmonary artery hypertension, and pulmonary embolism, etc.); (3) who had no severe heart, brain, liver, kidney, and hematopoietic diseases other than respiratory diseases; (4) able to complete the questionnaire; (5) no missing data of FEV1, FVC, modified Medical British Research Council (mMRC) scale, COPD Assessment Test (CAT) score, or diagnostic delay.

We performed the study in the form of questionnaires, including a self-made questionnaire, CAT questionnaire, and mMRC dyspnoea scale. Face-to-face interviews were conducted among participants by speciallyassigned persons. The self-made questionnaire included sex, age, number of acute exacerbations in the previous year, smoking pack-years, FEV1\% predicted, FEV1/FVC, residence, resident manner, years of education, medical insurance, diagnostic delay, hospital classification for first seeking-treatment visit, and previous history of pulmonary function test. Diagnostic delay was defined as the time interval from the onset of symptoms to physician-defined diagnosis of COPD, and it was expressed in days.

Statistical analysis. Data were analysed using Statistical Package for Social Sciences (SPSS) version 21.0. The data in this study were non-normally distributed after the normality test. Descriptive data without normal distribution were expressed as medians (interquartile range $[\mathrm{IQR}]$ ), and frequencies were expressed as numbers (percentage). The Wilcoxon and Kruskal-Wallis $\mathrm{H}$ tests were used to compare the diagnostic delay classified by outpatients' demographic variables. Multivariable linear regression analysis was performed to determine potential factors related to diagnostic delay. Statistical significance was set at $p<0.05$.

\section{Results}

Demographic characteristics. From the original queue including 530 outpatients, 122 patients were excluded. Of these, 38 patients didn't have a confirmed spirometry-verified COPD, 11 patients had a primary diagnosis of other respiratory diseases other than COPD, 12 were unable to complete the questionnaire, and 61 patients had missing data. Finally, a total of 408 outpatients meeting the eligible criteria were included (Fig. 1). 


\begin{tabular}{|c|c|}
\hline Characteristics & $n=408$ \\
\hline \multicolumn{2}{|l|}{ Sex } \\
\hline Male & $368(90.2 \%)$ \\
\hline Female & $40(9.8 \%)$ \\
\hline Age (years) & $65(58-69)$ \\
\hline \multicolumn{2}{|c|}{ Number of acute exacerbations in the previous year } \\
\hline 0 & $170(41.7 \%)$ \\
\hline 1 & $111(27.2 \%)$ \\
\hline$\geq 2$ & $127(31.1 \%)$ \\
\hline FEV1\% predicted & $53.3(35.0-69.2)$ \\
\hline CAT score & $13(8-18)$ \\
\hline mMRC scale & $2(1-3)$ \\
\hline \multicolumn{2}{|l|}{ Residence } \\
\hline City & $135(33.1 \%)$ \\
\hline Rural area & $273(66.9 \%)$ \\
\hline \multicolumn{2}{|l|}{ Resident manner } \\
\hline Living alone & $32(7.8 \%)$ \\
\hline Not living alone & $376(92.2 \%)$ \\
\hline Years of education & $9(6-9)$ \\
\hline \multicolumn{2}{|l|}{ Medical insurance } \\
\hline Yes & $399(97.8 \%)$ \\
\hline No & $9(2.2 \%)$ \\
\hline Diagnostic delay (days) & $230(50-720)$ \\
\hline \multicolumn{2}{|c|}{ Hospital classification for the first seeking-treatment visit } \\
\hline First-level hospital (I) & $67(16.4 \%)$ \\
\hline Secondary hospital (II) & $122(29.9 \%)$ \\
\hline Tertiary hospital (III) & $219(53.7 \%)$ \\
\hline \multicolumn{2}{|c|}{ Receiving PFT during the first seeking-treatment visit } \\
\hline Yes & $193(47.3 \%)$ \\
\hline No & $215(52.7 \%)$ \\
\hline
\end{tabular}

Table 1. Descriptive statistics of the outpatients' demographic characteristics. FEV1 forced expiratory volume in one second, CAT COPD Assessment Test, $m M R C$, modified Medical British Research Council, PFT pulmonary function test.

\begin{tabular}{|l|l|l|l|l|}
\hline PFT, $\mathbf{n}(\%)$ & $\begin{array}{l}\text { First-level hospital (I) } \\
\mathbf{n = 6 7}\end{array}$ & $\begin{array}{l}\text { Secondary hospital (II) } \\
\mathbf{n = 1 2 2}\end{array}$ & $\begin{array}{l}\text { Tertiary hospital (III) } \\
\mathbf{n = 2 1 9}\end{array}$ & p-value \\
\hline Yes & $1(1.5 \%)$ & $30(24.6 \%)$ & $162(74.0 \%)$ & $<0.001$ \\
\hline No & $66(98.5 \%)$ & $92(75.4 \%)$ & $57(26.0 \%)$ & \\
\hline
\end{tabular}

Table 2. Proportion of patients receiving PFT during the first seeking-treatment visit among different levels of hospitals. PFT pulmonary function test.

Table 1 depicts the outpatients' demographic characteristics. Males constituted $90.2 \%$ of the respondent group, while $9.8 \%$ were females. Of the included patients, $41.7 \%$ had no acute exacerbation, $27.2 \%$ had an acute exacerbation, and $31.1 \%$ had two or more acute exacerbations in the previous year. Nearly two-thirds of the participants lived in rural areas and 33.1\% lived in cities. A vast majority (92.2\%) of the patients did not live alone, while $7.8 \%$ lived alone. Almost all patients $(97.8 \%)$ had medical insurance in this study, except for $2.2 \%$ who did not. The median duration of diagnostic delay was 230 (50-720) days. Of the respondents, $16.4 \%$ chose firstlevel hospitals for their first visit, $29.9 \%$ chose secondary hospitals, and 53.7\% chose tertiary hospitals for their first visit. Almost half (47.3\%) of the patients underwent pulmonary function tests during their first visit, while $52.7 \%$ did not. Moreover, with the increase in hospital level, the proportion of patients undergoing pulmonary function test during the first visit gradually increased $(p<0.001)$ (Table 2).

Analysis of potential influencing factors associated with diagnostic delay. Tables 3 and 4 report the findings of the Wilcoxon test and the Kruskal-Wallis $\mathrm{H}$ analysis, which were performed to explore the differences of diagnostic delay among different characteristics. In terms of diagnostic delay, there were significant differences between rural areas and cities, living alone and not living alone, CAT $<10$ and CAT $\geq 10$, and $\mathrm{mMRC}<2$ 


\begin{tabular}{|l|l|c|}
\hline Characteristics & Diagnostic delay (days) & p-value \\
\hline Sex & $210(42-720)$ & 0.209 \\
\hline Male & $430(91-1028)$ & \\
\hline Female & \multicolumn{3}{|l|}{} \\
\hline Residence & $100(90-915)$ & $<0.001$ \\
\hline Rural area & $(18-390)$ & \\
\hline City & 0.001 \\
\hline Resident manner & $660(248-2645)$ & \\
\hline Living alone & $200(40-680)$ & $<0.001$ \\
\hline Not living alone & $119(30-353)$ & \\
\hline CAT score & $300(90-1080)$ & $<0.001$ \\
\hline$<10$ & $95(28-300)$ & \\
\hline$\geq 10$ & $300(90-1045)$ & 0.102 \\
\hline mMRC scale & $50(210-720)$ & \\
\hline$<2$ & $600(269-1710)$ & \\
\hline$\geq 2$ &
\end{tabular}

Table 3. Wilcoxon test for demographic differences in diagnostic delay. CAT, COPD Assessment Test, $m M R C$, modified Medical British Research Council, PFT pulmonary function test.

\begin{tabular}{|c|c|c|}
\hline Characteristics & Diagnostic delay (days) & p-value \\
\hline \multicolumn{3}{|l|}{ Age } \\
\hline$<50$ years & $29(10-125)$ & $<0.001$ \\
\hline $50-60$ years & $200(50-630)$ & \\
\hline $60-70$ years & $210(38-848)$ & \\
\hline$\geq 70$ years & $300(99-1025)$ & \\
\hline \multicolumn{3}{|c|}{ FEV1\% predicted } \\
\hline$<30 \%$ & $535(163-2700)$ & $<0.001$ \\
\hline $30-50 \%$ & $330(120-1440)$ & \\
\hline $50-80 \%$ & $140(30-540)$ & \\
\hline$\geq 80 \%$ & $60(14-300)$ & \\
\hline \multicolumn{2}{|c|}{ Number of acute exacerbations in the previous year } & 0.376 \\
\hline 0 & $200(47-613)$ & \\
\hline 1 & $240(40-930)$ & \\
\hline$\geq 2$ & $270(63-900)$ & \\
\hline \multicolumn{3}{|c|}{ Years of education } \\
\hline$\leq 6$ years & $360(110-1410)$ & $<0.001$ \\
\hline 7 to $\leq 9$ years & $210(30-588)$ & \\
\hline$>9$ years & $99(14-300)$ & \\
\hline
\end{tabular}

Table 4. Kruskal-Wallis $\mathrm{H}$ analysis for demographic differences in diagnostic delay. FEV1 forced expiratory volume in one second.

and $\mathrm{mMRC} \geq 2$ (all $p<0.01)$. There were also significant differences among participants classified by age, FEV $1 \%$ predicted, and years of education (all $p<0.001$ ).

Table 5 demonstrates linear regression analysis of potential influencing factors that may be associated with diagnostic delay. Linear regression analysis showed that significant predictors of diagnostic delay included FEV1\% predicted $(p<0.05)$, resident manner $(p<0.001)$, and years of education $(p<0.01)$.

\section{Discussion}

To the best of our knowledge, this is the first study to investigate the diagnostic delay and its influencing factors in COPD patients. Our study indicated that COPD patients had varying degrees of diagnostic delay (median [IQR]: 230 [50-720] days). Another study showed the median delayed diagnosis interval in patients with alpha-1 antitrypsin deficiency was 2.9 years $^{16}$. In a recent retrospective study, it was found that nearly half of the liver 


\begin{tabular}{|c|c|c|c|c|c|}
\hline \multirow[b]{2}{*}{ Variables } & \multicolumn{2}{|c|}{$\begin{array}{l}\text { Unstandardized } \\
\text { coefficients }\end{array}$} & \multirow[b]{2}{*}{ Standardized coefficients } & \multirow[b]{2}{*}{ t } & \multirow[b]{2}{*}{ p-value } \\
\hline & B & Standard error & & & \\
\hline Sex & -163.5 & 301.1 & -0.026 & -0.543 & 0.587 \\
\hline Age & 15.9 & 11.5 & 0.067 & 1.383 & 0.167 \\
\hline Number of acute exacerbations in the previous year & -13.5 & 25.4 & -0.025 & -0.529 & 0.597 \\
\hline FEV $1 \%$ predicted & -10.8 & 4.9 & -0.130 & -2.216 & 0.027 \\
\hline CAT score & -1.7 & 18.4 & -0.006 & -0.092 & 0.927 \\
\hline mMRC scale & 173.8 & 125.8 & 0.094 & 1.381 & 0.168 \\
\hline Residence & 183.1 & 201.8 & 0.045 & 0.907 & 0.365 \\
\hline Resident manner & 1433.2 & 340.0 & 0.203 & 4.215 & $<0.001$ \\
\hline Years of education & -93.4 & 27.3 & -0.171 & -3.420 & 0.001 \\
\hline Medical insurance & 617.5 & 616.4 & 0.048 & 1.002 & 0.317 \\
\hline
\end{tabular}

Table 5. Regression analysis of potential factors related to diagnostic delay. FEV1 forced expiratory volume in one second, CAT COPD Assessment Test, $m M R C$ modified Medical British Research Council.

cirrhosis patients delayed the diagnosis of hepatocellular carcinoma (HCC) in 60 days or more after danger signs $^{17}$. A new study from the United Kingdom has shown that diagnostic delay may exist in patients with inflammatory bowel disease (IBD); precisely, $92 \%$ of the patients were diagnosed within 2 years of the development of the symptoms and $50 \%$ were diagnosed within 4 months ${ }^{18}$. The diagnostic delay in COPD patients was relatively long, which might result from COPD being a chronic disease with a longer disease process and gradual aggravation of symptoms.

Previous studies have shown that the proportion of COPD patients who have undergone pulmonary function tests is not high ${ }^{10,19}$. However, these studies did not analyse the relationship between the proportion of patients receiving pulmonary function tests and hospital classifications. As expected, the proportion of patients whose first diagnosis institution was a high-level hospital, who underwent pulmonary function tests, was much higher than that of patients who visited primary hospitals. Therefore, the classification of hospitals is more conducive to understanding the true status of patients' lung function. In addition, this also illustrates the importance of propagating and popularising lung function tests in primary hospitals.

Our study indicated that the diagnostic delay of outpatients living in rural areas was significantly longer than that for those living in cities, and this may result from that COPD patients living in rural areas have poorer access to medical resource. Our study also found that resident manner was a significantly influencing factor of diagnostic delay in COPD patients. Elderly people living alone have an increased risk of depressive symptoms directly or indirectly by their reduced sense of belonging ${ }^{20}$. We speculated that patients living alone might be due to the lack of supervision from family members or financial constraints, and emotional depression increased the possibility of delay in seeking medical treatments. Interestingly, we found that the higher the disease severity (CAT, mMRC, and FEV1\% predicted) of COPD patients, the longer their visits were delayed, which was different from our original assumptions. We thought that symptoms of patients in the early disease stage were mild and had no significant impact on daily life, so patients did not seek medical treatments in time; thus, the diagnostic delay naturally increased as the disease developed. Tejwani et al. also concluded that for each additional year of diagnostic delay, the subject's FEV $1 \%$ predicted decreased by $0.3 \%$ in patients with alpha- 1 antitrypsin deficiency ${ }^{16}$. Besides, our results showed that the diagnostic delay of COPD patients continued to decrease with the increase of education years. A Chinese study reflected that there might be correlation between educational levels and COPD disease risks ${ }^{21}$. We speculated that patients with lower educational level might have poorer awareness of seeking medical care.

This study has some limitations. Firstly, since this study was restricted to outpatients from a single center, the results should be generalised with caution. Future studies should examine other public and private hospitals to more broadly explore diagnostic delay and its influencing factors in patients with COPD. Secondly, the relationship between knowledge level and diagnostic delay was not investigated as there might exist significant variances between newly diagnosed patients and previously diagnosed patients. Thirdly, we didn't perform interventions targeting influencing factors of diagnostic delay, and future prospective studies are needed to address this issue.

\section{Conclusions}

Our study indicates that varying degrees of diagnostic delay may exist in patients with COPD. Measures are needed to intervene in the potential factors associated with diagnostic delay.

Received: 18 January 2021; Accepted: 24 June 2021

Published online: 09 July 2021

\section{References}

1. López-Campos, J. L., Tan, W. \& Soriano, J. B. Global burden of COPD. Respirology 21(1), 14-23. https://doi.org/10.1111/resp. 12660 (2016). 
2. GBD 2013 Mortality and Causes of Death Collaborators. Global, regional, and national age-sex specific all-cause and cause-specific mortality for 240 causes of death, 1990-2013: A systematic analysis for the Global Burden of Disease Study 2013. Lancet 385(9963), 117-171. https://doi.org/10.1016/S0140-6736(14)61682-2 (2015).

3. Wang, C. et al. Prevalence and risk factors of chronic obstructive pulmonary disease in China (the China Pulmonary Health [CPH] study): A national cross-sectional study. Lancet 391(10131), 1706-1717. https://doi.org/10.1016/S0140-6736(18)30841-9 (2018).

4. Welte, T., Vogelmeier, C. \& Papi, A. COPD: Early diagnosis and treatment to slow disease progression. Int. J. Clin. Pract. 69(3), 336-349. https://doi.org/10.1111/ijcp.12522 (2015).

5. Decramer, M. et al. Effect of tiotropium on outcomes in patients with moderate chronic obstructive pulmonary disease (UPLIFT): A prespecified subgroup analysis of a randomised controlled trial. Lancet 374(9696), 1171-1178. https://doi.org/10.1016/S01406736(09)61298-8 (2009).

6. Zhou, Y. et al. Tiotropium in early-stage chronic obstructive pulmonary disease. N. Engl. J. Med. 377(10), 923-935. https://doi. org/10.1056/NEJMoa1700228 (2017).

7. Jenkins, C. R. et al. Efficacy of salmeterol/fluticasone propionate by GOLD stage of chronic obstructive pulmonary disease: Analysis from the randomised, placebo-controlled TORCH study. Respir. Res. 10(1), 59. https://doi.org/10.1186/1465-9921-10-59 (2009).

8. Jagana, R., Bartter, T. \& Joshi, M. Delay in diagnosis of chronic obstructive pulmonary disease: Reasons and solutions. Curr. Opin. Pulm. Med. 21(2), 121-126. https://doi.org/10.1097/MCP.0000000000000133 (2015).

9. Singh, D. et al. Global strategy for the diagnosis, management, and prevention of chronic obstructive lung disease: The GOLD science committee report 2019. Eur. Respir. J. 53(5), 1900164. https://doi.org/10.1183/13993003.00164-2019 (2019).

10. Hwang, Y. I. et al. Male current smokers have low awareness and optimistic bias about COPD: Field survey results about COPD in Korea. Int. J. Chron. Obstruct Pulmon. Dis. 14, 271-277. https://doi.org/10.2147/COPD.S189859 (2019).

11. Sikjær, M. G., Hilberg, O., Fløe, A., Dollerup, J. \& Løkke, A. Lack of awareness towards smoking-related health risks, symptoms related to COPD, and attitudinal factors concerning smoking: an Internet-based survey conducted in a random sample of the Danish general population. Eur. Clin. Respir. J. 5(1), 1506235. https://doi.org/10.1080/20018525.2018.1506235 (2018).

12. Behavior Medicine 470-493 (Hunan Science and Technology Press, 1999).

13. Larsson, K. et al. Impact of COPD diagnosis timing on clinical and economic outcomes: The ARCTIC observational cohort study. Int. J. Chron. Obstruct Pulmon. Dis. 2019(14), 995-1008. https://doi.org/10.2147/COPD.S195382 (2019).

14. Wang, Y., Long, Q., Liu, Q., Tolhurst, R. \& Tang, S. Treatment seeking for symptoms suggestive of TB: Comparison between migrants and permanent urban residents in Chongqing, China. Trop. Med. Int. Health 13(7), 927-933. https://doi.org/10.1111/j. 1365-3156.2008.02093.x (2008).

15. Global Strategy for the Diagnosis, Management, and Prevention of Chronic Obstructive Pulmonary Disease 2019 Report. https:// www.goldcopdorg/wp-content/uploads/2018/11/GOLD-2019-v17-FINAL-14Nov2018-WMSpdf (Accessed 23 April 2019).

16. Tejwani, V., Nowacki, A. S., Fye, E., Sanders, C. \& Stoller, J. K. The impact of delayed diagnosis of alpha-1 antitrypsin deficiency: The association between diagnostic delay and worsened clinical status. Respir. Care 64(8), 915-922. https://doi.org/10.4187/respc are.06555 (2019).

17. Choi, D. T. et al. Factors associated with delay of diagnosis of hepatocellular carcinoma in patients with cirrhosis. Clin. Gastroenterol. Hepatol. https://doi.org/10.1016/j.cgh.2020.07.026 (2020).

18. Walker, G. J. et al. Quality improvement project identifies factors associated with delay in IBD diagnosis. Aliment Pharmacol. Ther. 52(3), 471-480. https://doi.org/10.1111/apt.15885 (2020).

19. Lee, H. Y. et al. Clinical characteristics and economic burden of tuberculous-destroyed lung in Korea: A National Health Insurance Service-National Sample Cohort-based study. J. Thorac. Dis. 11(6), 2324-2331. https://doi.org/10.21037/jtd.2019.06.14 (2019).

20. McLaren, S. The Relationship between living alone, sense of belonging, and depressive symptoms among older men: The moderating role of sexual orientation. Aging Ment. Health 24(1), 103-109. https://doi.org/10.1080/13607863.2018.1531373 (2020).

21. Cai, L. et al. Socioeconomic variations in chronic obstructive pulmonary disease prevalence, diagnosis, and treatment in rural Southwest China. BMC Public Health 20(1), 536. https://doi.org/10.1186/s12889-020-08687-5 (2020).

\section{Author contributions}

Y.C. and P.C. designed the study. Z.D. and Y.M. wrote the manuscript. Z.D., Y.M. and Z.Z. performed the statistical analysis. All authors reviewed the manuscript.

\section{Funding}

The funding was provided by National Natural Science Foundation of China (No. 81873410 and No.82070049) and also by National Key R\&D Program of China (2016YFC1304700).

\section{Competing interests}

The authors declare no competing interests.

\section{Additional information}

Correspondence and requests for materials should be addressed to P.C. or Y.C.

Reprints and permissions information is available at www.nature.com/reprints.

Publisher's note Springer Nature remains neutral with regard to jurisdictional claims in published maps and institutional affiliations.

(c) (i) Open Access This article is licensed under a Creative Commons Attribution 4.0 International License, which permits use, sharing, adaptation, distribution and reproduction in any medium or format, as long as you give appropriate credit to the original author(s) and the source, provide a link to the Creative Commons licence, and indicate if changes were made. The images or other third party material in this article are included in the article's Creative Commons licence, unless indicated otherwise in a credit line to the material. If material is not included in the article's Creative Commons licence and your intended use is not permitted by statutory regulation or exceeds the permitted use, you will need to obtain permission directly from the copyright holder. To view a copy of this licence, visit http://creativecommons.org/licenses/by/4.0/.

(C) The Author(s) 2021 